\title{
The application of double-layer remote phosphor structures in increasing WLEDs color rendering index and lumen output
}

\author{
Nguyen Thi Phuong Loan', Nguyen Doan Quoc Anh' \\ ${ }^{1}$ Faculty of Fundamental 2, Posts and Telecommunications Institute of Technology, Vietnam \\ ${ }^{2}$ Power System Optimization Research Group, Faculty of Electrical and Electronics Engineering, \\ Ton Duc Thang University, Vietnam
}

\begin{tabular}{l} 
Article Info \\
\hline Article history: \\
Received $\mathrm{Sep} 4,2019$ \\
Revised Apr 27, 2020 \\
Accepted May 7, 2020 \\
\hline Keywords: \\
$(\mathrm{Ce}, \mathrm{Tb}) \mathrm{MgAl}_{11} \mathrm{O}_{19}: \mathrm{Ce}: \mathrm{Tb}$ \\
Color uniformity \\
Luminous efficacy \\
$\mathrm{MgSr}_{3} \mathrm{Si}_{2} \mathrm{O}_{8}: \mathrm{Eu}^{2+}, \mathrm{Mn}^{2+}$ \\
$\mathrm{Mie}^{2+} \mathrm{Scattering} \mathrm{theory}^{2}$
\end{tabular}

Article Info

ticle history:

Received Sep 4, 2019

Revised Apr 27, 2020

\begin{abstract}
The remote phosphor structure often has inferior color quality but better luminous flux in than conformal or in-cup configurations. Therefore, numerous researches study remote phosphor structure for methods to enhance it chromatic quality. This study introduces the use of dual-layer remote phosphor structure in WLEDs with identical structure but at different color temperature, $6600 \mathrm{~K}$ and $7700 \mathrm{~K}$, to demonstrate their effect on quality indicators. The concept is placing a green phosphor layer $(\mathrm{Ce}, \mathrm{Tb}) \mathrm{MgAl}_{11} \mathrm{O}_{19}: \mathrm{Ce}: \mathrm{Tb}$ or a red phosphor layer $\mathrm{MgSr}_{3} \mathrm{Si}_{2} \mathrm{O}_{8}: \mathrm{Eu}^{2+}, \mathrm{Mn}^{2+}$ on the layer of yellow-emitting phosphor YAG: $\mathrm{Ce}^{3+}$ and find the suitable concentration of the additional phosphor to create the best color quality. The results showed that the increase of CRI and CQS are affected by $\mathrm{MgSr}_{3} \mathrm{Si}_{2} \mathrm{O}_{8}: \mathrm{Eu}^{2+}, \mathrm{Mn}^{2+}$, in particular, the higher the concentration of red phosphor gets the better CRI and CQS because the emitted red light in enhanced. The green phosphor layer $(\mathrm{Ce}, \mathrm{Tb}) \mathrm{MgAl}_{11} \mathrm{O}_{19}: \mathrm{Ce}: \mathrm{Tb}$, on the other hand, is beneficial for the luminous flux. The concentration of $\mathrm{MgSr}_{3} \mathrm{Si}_{2} \mathrm{O}_{8}: \mathrm{Eu}^{2+}, \mathrm{Mn}^{2+}$ and $(\mathrm{Ce}, \mathrm{Tb}) \mathrm{MgAl}_{11} \mathrm{O}_{19}: \mathrm{Ce}: \mathrm{Tb}$, however, need to be adjusted properly to avoid decreasing the luminous flux due to overgrowth. The Mie scattering theory and Beer's law are the verification tools for these conclusions, which gives them the credibility to be applied in producing better quality WLEDs.
\end{abstract}

Copyright $(0) 2020$ Institute of Advanced Engineering and Science. All rights reserved.

\section{Corresponding Author:}

Nguyen Doan Quoc Anh,

Power System Optimization Research Group,

Faculty of Electrical and Electronics Engineering,

Ton Duc Thang University,

No. 19 Nguyen Huu Tho Street, Tan Phong Ward, District 7, Ho Chi Minh City, Vietnam.

Email: nguyendoanquocanh@tdtu.edu.vn

\section{INTRODUCTION}

The fourth potential generation lighting method, the white light emitting diodes with phosphor coated on the outside (pc-WLEDs), has many positive traits than the conventional one, and thus, it replaced and posed itself as an optimal lighting solution [1]. The remarkable traits of white light-emitting diodes stimulate the widespread usage in many aspects of our lighting needs from aesthetic lighting and backlighting to the practical purpose of street lighting, etc. However, the light efficiency in light extraction and the balance of radian intensity distribution to stabilize correlated color temperature are the two obstacles prevent further developments in WLEDs [2]. Therefore, to respond to the growing application needs and market demands, finding an innovation that relates to luminous efficiency and color quality is inevitable [3]. White light are often a product of combination between blue light from and yellow light from distinct light sources. The idea may be similar but the benefits that LEDs configuration and the set up phosphor layers bring to the luminous efficiency, and the color quality is significant [4-8]. Besides, many other options to 
coat phosphor such as dispersed coating and conformal coating were presented to produce LEDs, however, fail to replicate the equivalent effect $[9,10]$. The problem is that the contact surface between the LED and phosphor layer heats up due to yellow emitting phosphor come in contact directly with the LED chip, which causes the amount of light converted from phosphor material to decline and therefore unable to yield high color quality. So, in order to boost phosphor efficiency and prevent unwanted impairment on the phosphor, the reduction of generated heat is desirable. As a result, the remote phosphor structure with separated phosphor and heat source (LED chip) configuration was proposed in different studies as a possible solution for the aforementioned problem. The space that separate the phosphor materials from the LED chip is enough for proper adjustment in backscattering and inner circulation of light, which make this method effective and beneficial to luminous efficiency and the color quality in LEDs [11, 12]. However, creating a better LED is still an imminent goal as the remote phosphor structure is only suitable for standard lighting situation but unable to reply to higher lighting requirements.

Concerning creating a better LED, many unconventional structures with many different advantages such as reduced backscattering effect and improved luminous efficiency are brought out. One of the studies presented a structure contains an inverted and enclosed cone lens and an encompassing ring remote phosphor layer that can divert the emitted LED light from the chip outside of structure which reduces the damage from internal reflection LED [13]. Another one is the use of a patterned remote phosphor structure with an empty perimeter that has no coating phosphor on the surrounding surface in achieving better angular-dependent correlated color temperature and high chromatic stability [14]. In addition, the remote phosphor structure that has the patterned sapphire substrate in it perform better than a common pattern as benefits the uniformity of correlated color temperature in the radiation-zone field [15]. The proposal suggest using remote phosphor structure WLED with two phosphor layers to achieve the goal of enhancing the light emitted from LEDs.

The studies listed above all focus on improving color homogeneity and light output of WLEDs in the remote phosphor structure. However, those studies only concentrated on the WLEDs configurations with a single chip and at low correlated color temperatures while a more difficult task is to improve the optical properties of WLEDs with high correlated color temperatures. As acknowledging this important goal, Anh and his partners have conducted two different researches demonstrating the how the application of double layers of phosphor in WLEDs can influences the quality indicators, specifically on lumen output and color uniformity [16-18]. In the first study, the dual-remote phosphor with flat layers (FDRP) were compared with concave dual-remote phosphor (CDRP) to figure out which is more advantageous to WLEDs packages. They also explained how the gap between phosphor in dual-layers structure affects the luminous efficiency and color quality of WLEDs. The attained results showed that FDRP is superior than CDRP, and the distance $\mathrm{d}_{1}=0.08 \mathrm{~mm}$ or $\mathrm{d}_{2}=0.63 \mathrm{~mm}$ is beneficial to the luminous flux while the distance $\mathrm{d}_{1}>0.08 \mathrm{~mm}$ or $\mathrm{d}_{2}>0.63$ helps to increase the chromatic homogeneity. However, this article did not propose any type of phosphor to enhance the quality of LEDs. Therefore, in the second one, they work on the remote phosphor structure with two phosphor layers containing green phosphor $(\mathrm{Ce}, \mathrm{Tb}) \mathrm{MgAl}_{11} \mathrm{O}_{19}$ : $\mathrm{Ce}$ : $\mathrm{Tb}$. This work obtained useful results by investigating the effects of different concentration of $(\mathrm{Ce}, \mathrm{Tb}) \mathrm{MgAl}_{11} \mathrm{O}_{19}$ : $\mathrm{Ce}: \mathrm{Tb}$ with three color temperatures $5600 \mathrm{~K}, 6600 \mathrm{~K}$ and $7700 \mathrm{~K}$. Specifically, the increase of $(\mathrm{Ce}, \mathrm{Tb}) \mathrm{MgAl}_{11} \mathrm{O}_{19}: \mathrm{Ce}: \mathrm{Tb}$ concentration benefits the luminous flux but has a small disadvantage to CRI if it is excessive; and this phosphor can enhance the color quality due to its absorption characteristics.

In another paper, they continued to research the influence of the distances between phosphor layer but this time, the investigated one is the triple-layer structure. They simulate the structure with green and red phosphor above the yellow one, yet the specific red and green phosphors have not mentioned. The results presented that when the distance $d=0.64$, the luminous flux enhances by $9.7 \%$, while $d=0.84$, it benefits the color uniformity. Though the results from these studies are important for WLEDs production, the choices of dual-layer phosphor structures are limited as there is no comparison about the effectiveness of dual-layer phosphor configuration compared to the others. Therefore, to help manufacturers have references to select the most appropriate dual-layer phosphor structure for accomplishing the improvement of color quality or enhancement the luminous flux emitted, in this article, we will propose two different types of dual-layer remote structures of green $(\mathrm{Ce}, \mathrm{Tb}) \mathrm{MgAl}_{11} \mathrm{O}_{19}: \mathrm{Ce}: \mathrm{Tb}$ and red $\mathrm{MgSr}_{3} \mathrm{Si}_{2} \mathrm{O}_{8}: \mathrm{Eu}^{2+}, \mathrm{Mn}^{2+}$. Moreover, based on the results of three studies above and this article's experiments, we will make a detailed comparison between them in terms of color quality and luminous flux, which has not done in aforementioned studies.

This article proposes two dual-layer remote structure for WLEDs color quality development at distinct colors temperature of $6600 \mathrm{~K}$ and $7700 \mathrm{~K}$. The first idea is to employ the green phosphor layer $(\mathrm{Ce}, \mathrm{Tb}) \mathrm{MgAl}_{11} \mathrm{O}_{19}: \mathrm{Ce}: \mathrm{Tb}$ in boosting green light component of WLEDs, resulting in an increase of luminous flux emitted. The second idea involves using the red phosphor layer $\mathrm{MgSr}_{3} \mathrm{Si}_{2} \mathrm{O}_{8}: \mathrm{Eu}^{2+}, \mathrm{Mn}^{2+}$ to benefit CRI and CQS by boosting the red light component in WLEDs. The article also describes in detail the influences the chemical compositions of $\mathrm{MgSr}_{3} \mathrm{Si}_{2} \mathrm{O}_{8}: \mathrm{Eu}^{2+}, \mathrm{Mn}^{2+}$ has on optical properties of WLEDs. The addition of the phosphor layer $\mathrm{MgSr}_{3} \mathrm{Si}_{2} \mathrm{O}_{8}: \mathrm{Eu}^{2+}, \mathrm{Mn}^{2+}$ is proven to be beneficial to the CRI and CQS by the conclusion of 
this article. However, the concentration of $(\mathrm{Ce}, \mathrm{Tb}) \mathrm{MgAl}_{11} \mathrm{O}_{19}: \mathrm{Ce}: \mathrm{Tb}$ and $\mathrm{MgSr}_{3} \mathrm{Si}_{2} \mathrm{O}_{8}: \mathrm{Eu}^{2+}, \mathrm{Mn}^{2+}$ have to be at the exact percentage to avoid damaging the color quality or luminous flux due to exceeding concentrations of red phosphor and green phosphor. Coating the green phosphor layer or the red phosphor layer over the yellow phosphor layer YAG: $\mathrm{Ce}^{3+}$ : create three changes, the first one is the emission spectrum of the white light increase accordingly to the amount of green light component or red light component added in, which is a prominent aspect of enhancing color performance. Second, the light scattering and transmission efficiency are contrast to the concentration of added phosphor layers. Therefore, selecting the appropriate concentration for the phosphors is vital in maintaining the luminous flux of WLEDs.

\section{PREPARATION PROCESS}

The physical model of WLEDs that are used in the experiments is presented in Figure 1(a) is the research subject for this study. The wattage of blue chip is $1.16 \mathrm{~W}$ with emission wavelength of $453 \mathrm{~nm}$. In Figure 1(b) are detailed optical properties of the constituents in the model. The remote phosphor structure is constructed and studied to identify the optimal concentration for $(\mathrm{Ce}, \mathrm{Tb}) \mathrm{MgAl}_{11} \mathrm{O}_{19}: \mathrm{Ce}: \mathrm{Tb}$ and $\mathrm{MgSr}_{3} \mathrm{Si}_{2} \mathrm{O}_{8}: \mathrm{Eu}^{2+}, \mathrm{Mn}^{2+}$. The dual-layer configuration with green-yellow phosphor package (GYC) and the dual-layer configuration with red-yellow phosphor package (RYC) are the main subjects in this research. The GYC structure includes two layers of phosphor covered the blue chip with the green phosphor $\mathrm{SrBaSiO}_{4}: \mathrm{Eu}^{2}$ above the yellow phosphor YAG:Ce ${ }^{3+}$ as in Figure 1(c). Figure 1(d) illustrate the RYC structure which the red phosphor $\mathrm{MgSr}_{3} \mathrm{Si}_{2} \mathrm{O}_{8}: \mathrm{Eu}^{2+}, \mathrm{Mn}^{2+}$ above the yellow phosphor YAG: $\mathrm{Ce}^{3+}$ instead. The purpose of using GYC and RYC structures is to find the correct concentration of (Ce, $\mathrm{Tb}) \mathrm{MgAl}_{11} \mathrm{O}_{19}: \mathrm{Ce}: \mathrm{Tb}$ and $\mathrm{MgSr}_{3} \mathrm{Si}_{2} \mathrm{O}_{8}: \mathrm{Eu}^{2+}, \mathrm{Mn}^{2+}$ that can boost the scattering effects as well as the green, red light components in WLEDs and then allows the performance of WLEDs to improve.

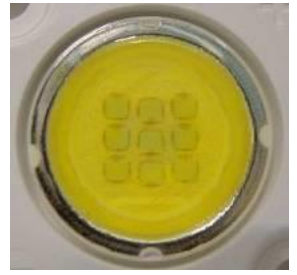

(a)
Lead frame: $4.7 \mathrm{~mm}$ Jentech Size-S LED chip: $\mathrm{V} 45 \mathrm{H}$

Die attach: Sumitomo 1295SA Gold Wire: $1.0 \mathrm{mil}$

Phosphor: ITC NYAG4_EL

(b)

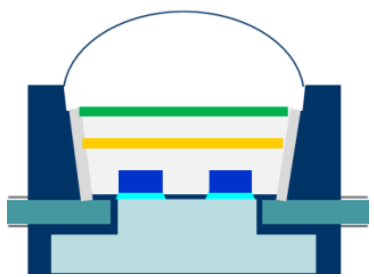

(c)

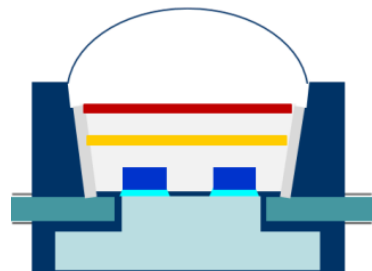

(d)

Figure 1. Illustration of phosphor-converted MCW-LEDs as doping (Ce,Tb) $\mathrm{MgAl}_{11} \mathrm{O}_{19}$ :Ce:Tb: (a) the actual MCW-LEDs and (b) its parameters; (c) illustration of GYC, and (d) RYC

In Figure 2 is the contrast in changes between the concentration of the green phosphor $(\mathrm{Ce}, \mathrm{Tb}) \mathrm{MgAl}_{11} \mathrm{O}_{19}: \mathrm{Ce}: \mathrm{Tb}$ and red phosphor $\mathrm{MgSr}_{3} \mathrm{Si}_{2} \mathrm{O}_{8}: \mathrm{Eu}^{2+}, \mathrm{Mn}^{2+}$ with yellow phosphor YAG: $\mathrm{Ce}^{3+}$. This change in concentration has two meanings; the first is to maintain the average CCTs and the other one is to influence the scattered light and absorption of both phosphor layers in WLEDs which certainly affects the color quality and luminous flux. Therefore, the concentrations of $(\mathrm{Ce}, \mathrm{Tb}) \mathrm{MgAl}_{11} \mathrm{O}_{19}: \mathrm{Ce}: \mathrm{Tb}$ and $\mathrm{MgSr}_{3} \mathrm{Si}_{2} \mathrm{O}_{8}: \mathrm{Eu}^{2+}, \mathrm{Mn}^{2+}$ are the deciding factors of color quality in WLEDs. When the concentration of $(\mathrm{Ce}, \mathrm{Tb}) \mathrm{MgAl}_{11} \mathrm{O}_{19}: \mathrm{Ce}: \mathrm{Tb}$ and $\mathrm{MgSr}_{3} \mathrm{Si}_{2} \mathrm{O}_{8}: \mathrm{Eu}^{2+}, \mathrm{Mn}^{2+}$ rise respectively from 2\%-20\% wt. and 2\%-26\% wt, the concentration of YAG: $\mathrm{Ce}^{3+}$ decrease to stabilize the CCTs at average level. This reaction is the same for other WLEDs with color temperatures of $6600 \mathrm{~K}$ and $7700 \mathrm{~K}$. The effects of red phosphor $\mathrm{MgSr}_{3} \mathrm{Si}_{2} \mathrm{O}_{8}: \mathrm{Eu}^{2+}, \mathrm{Mn}^{2+}$ and green phosphor $(\mathrm{Ce}, \mathrm{Tb}) \mathrm{MgAl}_{11} \mathrm{O}_{19}: \mathrm{Ce}: \mathrm{Tb}$ concentrations on the emission spectra in WLEDs are calculated and presented in Figure 3. The intensity trend in the two light spectrum areas 420-480 $\mathrm{nm}$ and 500-640 $\mathrm{nm}$ increase accordingly with the concentration of $(\mathrm{Ce}, \mathrm{Tb}) \mathrm{MgAl}_{11} \mathrm{O}_{19}$ : $\mathrm{Ce}: \mathrm{Tb}$; and it is the increase in the emission spectrum at these two areas that verified the increase in luminous flux.

Moreover, the presence of $(\mathrm{Ce}, \mathrm{Tb}) \mathrm{MgAl}_{11} \mathrm{O}_{19}: \mathrm{Ce}: \mathrm{Tb}$ greatly improves the blue-light scattering in WLEDs, which means the scattering effect in the phosphor layers and in WLEDs is developed. Consequently, the color homogeneity reaches a significant enhancement. Thus, these findings are important references in $(\mathrm{Ce}, \mathrm{Tb}) \mathrm{MgAl}_{11} \mathrm{O}_{19}$ : $\mathrm{Ce}: \mathrm{Tb}$ application. In terms of $\mathrm{MgSr}_{3} \mathrm{Si}_{2} \mathrm{O}_{8}: \mathrm{Eu}^{2+}, \mathrm{Mn}^{2+}$ influence, there are noticeable changes in the light spectrum area from $648 \mathrm{~nm}$ to $738 \mathrm{~nm}$ in accordance with the concentration of red phosphor $\mathrm{MgSr}_{3} \mathrm{Si}_{2} \mathrm{O}_{8}: \mathrm{Eu}^{2+}, \mathrm{Mn}^{2+}$. However, these changes are insignificant without the expansion of emission spectrum in the two remaining areas, $420-480 \mathrm{~nm}$ and $500-640 \mathrm{~nm}$, as the enhancement in these two emission spectra benefits the luminous flux of the scattered blue light. Furthermore, the higher the color temperature, the higher the spectral emission, resulting in higher color quality and better luminous flux. 
Therefore, this result is crucial to the application of $\mathrm{MgSr}_{3} \mathrm{Si}_{2} \mathrm{O}_{8}: \mathrm{Eu}^{2+}, \mathrm{Mn}^{2+}$, especially when controlling the quality of WLEDs with high temperature still remains a difficult task. In short, that $\mathrm{MgSr}_{3} \mathrm{Si}_{2} \mathrm{O}_{8}: \mathrm{Eu}^{2+}, \mathrm{Mn}^{2+}$ can benefits the chromatic performance of WLEDs at both low $(6600 \mathrm{~K})$ and high $(7700 \mathrm{~K})$ color temperature is confirmed in this study. Last but not least, the choices of phosphors and their concentrations can be changed depending on the demand of the manufacturers. If their desires are high quality WLEDs, a small loss in luminous flux can be permitted to suit those demands.

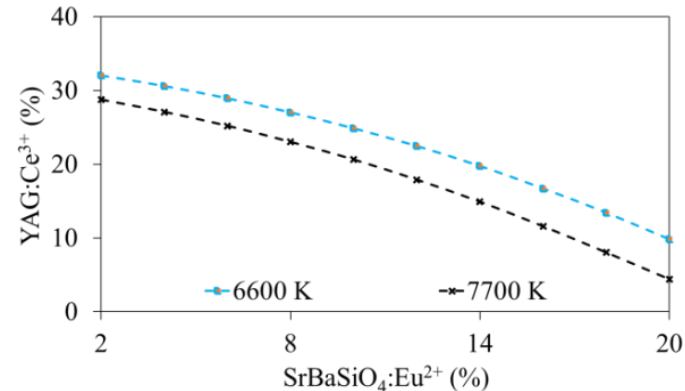

(a)

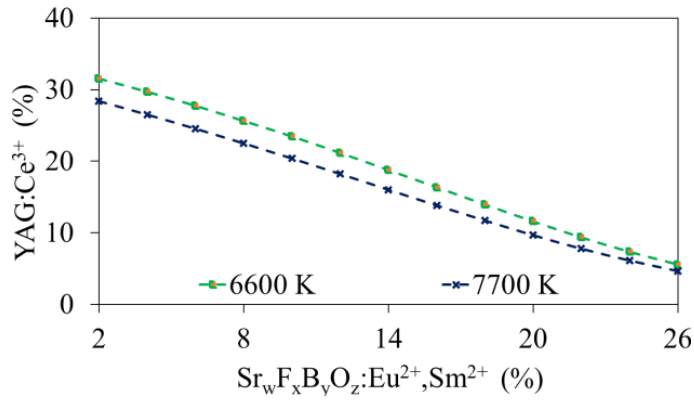

(b)

Figure 2. The change of phosphor concentration of GYC (a) and RYC (b) to keep the average CCTs

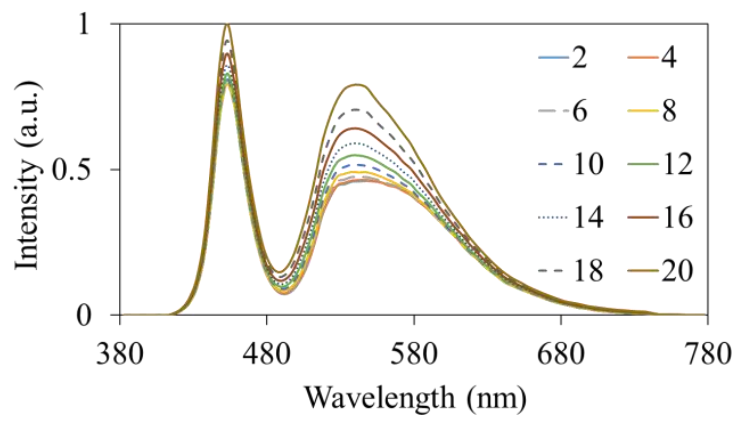

(a)

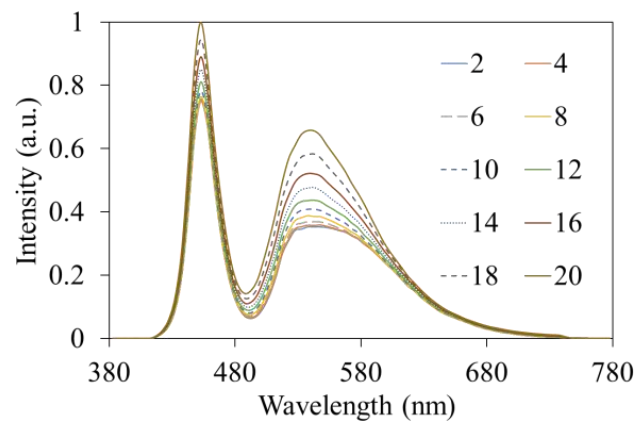

(c)

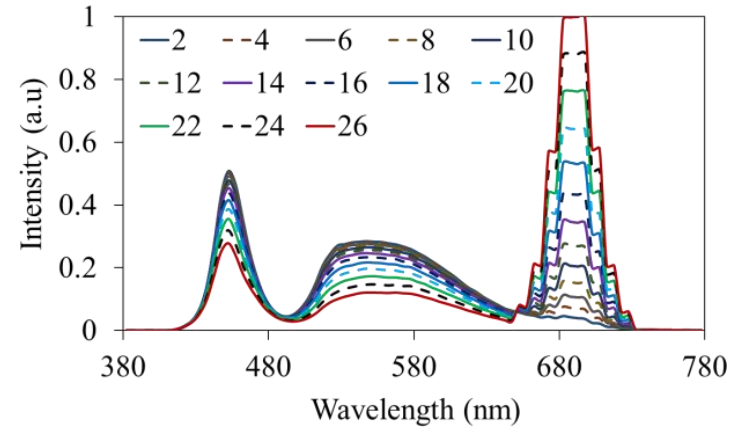

(b)

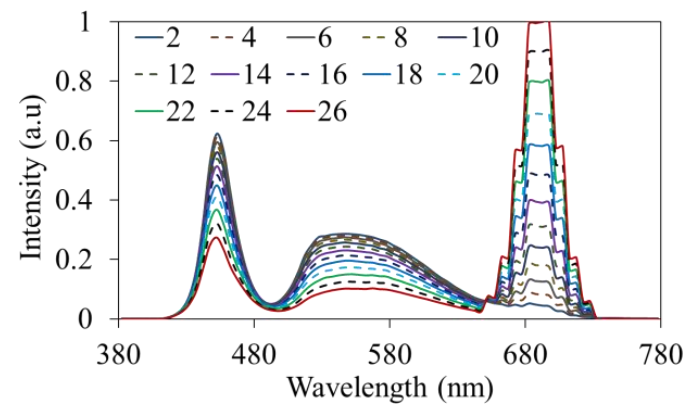

(d)

Figure 3. Emission spectra of dual-layer phosphor configurations:

(a) $6600 \mathrm{~K}$ - GYC; (b) $7700 \mathrm{~K}$ - GYC; (c) $6600 \mathrm{~K}$ - RYC; (d) $7700 \mathrm{~K}$ - RYC

\section{RESULTS AND ANALYSIS}

In Figure 4 are color rendering index (CRI) and color quality scale (CQS) corresponding to different concentrations of $(\mathrm{Ce}, \mathrm{Tb}) \mathrm{MgAl}_{11} \mathrm{O}_{19}: \mathrm{Ce}: \mathrm{Tb}$ and $\mathrm{MgSr}_{3} \mathrm{Si}_{2} \mathrm{O}_{8}: \mathrm{Eu}^{2+}, \mathrm{Mn}^{2+}$ phosphors. As can be seen, the CRI declines considerably when the concentration of $(\mathrm{Ce}, \mathrm{Tb}) \mathrm{MgAl}_{11} \mathrm{O}_{19}: \mathrm{Ce}: \mathrm{Tb}$ rises. The reason is that the exceeded green light causes an imbalance between the primary colors: blue, yellow and green, and thus, reduces the chromatic quality of WLEDs and damages their CRI indexes which assesses the color of the subjects when the light illuminates them. However, it is a tolerable drawback because CRI is a part of 
CQS and when comparing between the two, CQS stands out as a more important and challenging target. Specifically, CQS consists of three elements: color rendering index, viewer's preference and color coordinates. Thus, CQS seems to be an index that can give color quality an overall judgment. From the third graph in Figure 4, we can see that the CQS remains unchanged when the concentration of $(\mathrm{Ce}, \mathrm{Tb}) \mathrm{MgAl}_{11} \mathrm{O}_{19}: \mathrm{Ce}: \mathrm{Tb}$ is below $8 \%$. Therefore, $8 \%(\mathrm{Ce}, \mathrm{Tb}) \mathrm{MgAl}_{11} \mathrm{O}_{19}: \mathrm{Ce}: \mathrm{Tb}$ can be applied after considering the luminous flux. Meanwhile, the CRI increases with the rise of phosphor $\mathrm{MgSr}_{3} \mathrm{Si}_{2} \mathrm{O}_{8}: \mathrm{Eu}^{2+}, \mathrm{Mn}^{2+}$ concentration in all average CCTs; and this result has not been demonstrated in previous researches. This superior achievement is the results of red phosphor absorbing ability. When the red phosphor $\mathrm{MgSr}_{3} \mathrm{Si}_{2} \mathrm{O}_{8}: \mathrm{Eu}^{2+}, \mathrm{Mn}^{2+}$ takes in the light from the chips, these particles of red phosphor transform the emitted light from blue to red. Besides from the light of the chips, red phosphor $\mathrm{MgSr}_{3} \mathrm{Si}_{2} \mathrm{O}_{8}: \mathrm{Eu}^{2+}, \mathrm{Mn}^{2+}$ also consume the light of yellow phosphor. However, the comparison of these absorptions show that the blue light absorbed from the chips is superior because of the absorption characteristic of the material.

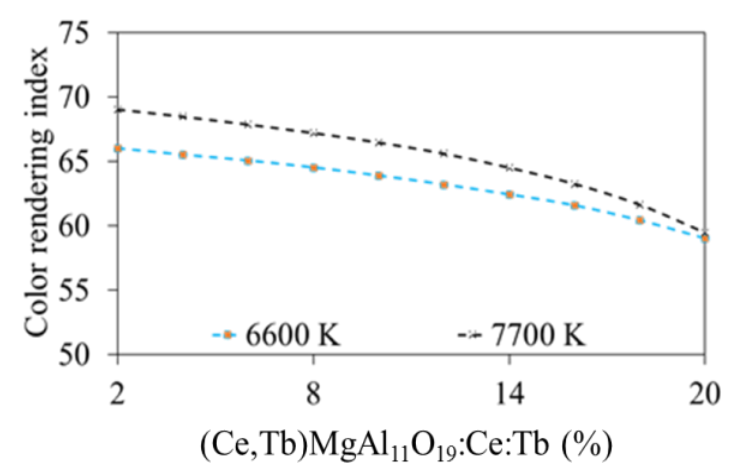

(a)

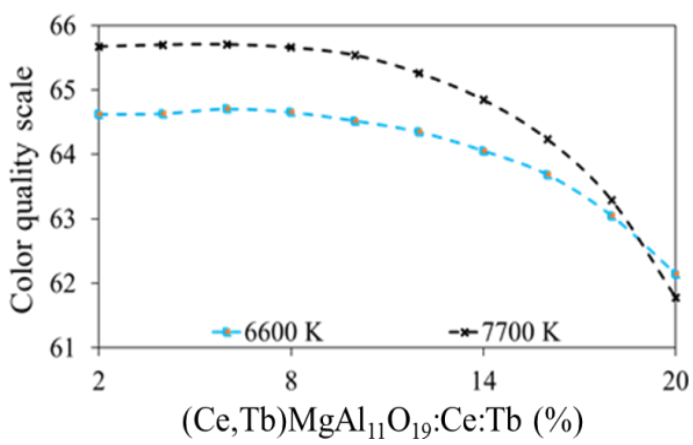

(c)

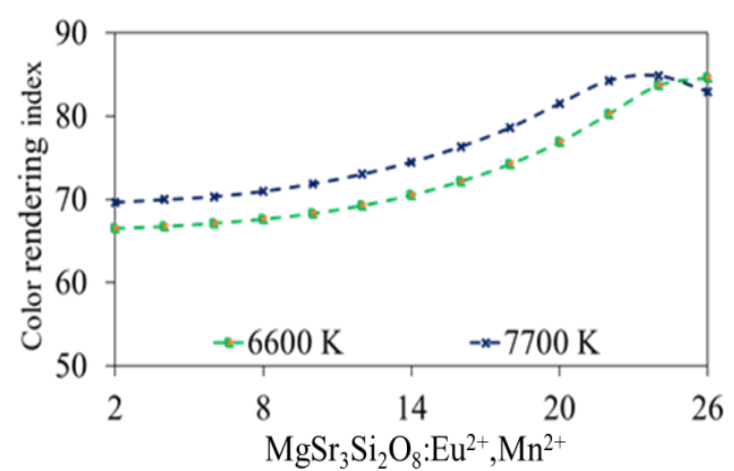

(b)

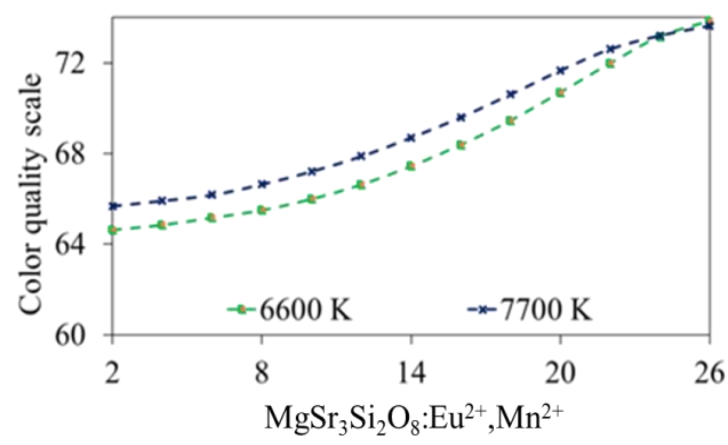

(d)

Figure 4. The color quality scale as a function of the concentration of $(\mathrm{Ce}, \mathrm{Tb}) \mathrm{MgAl}_{11} \mathrm{O}_{19}: \mathrm{Ce}: \mathrm{Tb}$ and $\mathrm{MgSr}_{3} \mathrm{Si}_{2} \mathrm{O}_{8}: \mathrm{Eu}^{2+}, \mathrm{Mn}^{2+}$

Hence, adding $\mathrm{MgSr}_{3} \mathrm{Si}_{2} \mathrm{O}_{8}: \mathrm{Eu}^{2+}, \mathrm{Mn}^{2+}$ results in an increase of red light components, which benefits the development of color rendering index (CRI). Moreover, color rendering index plays a crucial role in choosing a modern Led as the high quality WLED has high CRI. Besides, another advantage of $\mathrm{MgSr}_{3} \mathrm{Si}_{2} \mathrm{O}_{8}: \mathrm{Eu}^{2+}, \mathrm{Mn}^{2+}$ phosphor is cost-saving, thus, it can be widely used in LEDs production with the aim of high CRI. However, as mentioned above, color rendering index only evaluates certain aspects of light, in other words, having a high color rendering index does not mean the light quality is good. Hence, color quality scale (CQS) was proposed and becomes more important due to its comprehensiveness in light evaluation, as presented in the above paragraph. In contrast with $(\mathrm{Ce}, \mathrm{Tb}) \mathrm{MgAl}_{11} \mathrm{O}_{19}$ : $\mathrm{Ce}: \mathrm{Tb}, \mathrm{CQS}$ values are impressive with the participation of red phosphor $\mathrm{MgSr}_{3} \mathrm{Si}_{2} \mathrm{O}_{8}: \mathrm{Eu}^{2+}, \mathrm{Mn}^{2+}$. The last illustration of Figure 4 clearly shows a significant enhancement of CQS when the concentration of remote phosphor $\mathrm{MgSr}_{3} \mathrm{Si}_{2} \mathrm{O}_{8}: \mathrm{Eu}^{2+}, \mathrm{Mn}^{2+}$ layers grow. Thus, employing $\mathrm{MgSr}_{3} \mathrm{Si}_{2} \mathrm{O}_{8}: \mathrm{Eu}^{2+}, \mathrm{Mn}^{2+}$ is obviously beneficial to the quality of white light in WLEDs with dual-layer phosphor structure; and this is a useful finding of the study in regards to improving the color quality. Nevertheless, $\mathrm{MgSr}_{3} \mathrm{Si}_{2} \mathrm{O}_{8}: \mathrm{Eu}^{2+}, \mathrm{Mn}^{2+}$ also causes a great damage to the emitted flux, and this will be presented in the next part. In this part is the mathematical model 
used to calculate the transmitted blue light and converted yellow light in the double-layer phosphor structure. Moreover, this mathematical system will prove that the use of a double-layer phosphor structure can bring superior improvement to the lighting efficiency of WLEDs than the single one. Additionally, disadvantage of $\mathrm{MgSr}_{3} \mathrm{Si}_{2} \mathrm{O}_{8}: \mathrm{Eu}^{2+}, \mathrm{Mn}^{2+}$ phosphor layer to the luminous flux will be demonstrated through formulas below [19-23].

The emitted blue light and yellow light from light conversion for remote phosphor structure containing one phosphor layer with thickness described as $2 h$ are expressed as follows:

$$
\begin{aligned}
& P B_{1}=P B_{0} \times e^{-2 \alpha_{B 1} h} \\
& P Y_{1}=\frac{1}{2} \frac{\beta_{1} \times P B_{0}}{\alpha_{B 1}-\alpha_{Y 1}}\left(e^{-2 \alpha_{Y 1} h}-e^{-2 \alpha_{B 1} h}\right)
\end{aligned}
$$

The emitted blue light and yellow light from light conversion for remote phosphor package containing two phosphor layers with the layer thickness of $h$ are measured with:

$$
\begin{aligned}
& P B_{2}=P B_{0} \times e^{-2 \alpha_{B 2} h} \\
& P Y_{2}=\frac{1}{2} \frac{\beta_{2} \times P B_{0}}{\alpha_{B 2}-\alpha_{Y 2}}\left(e^{-2 \alpha_{Y 2} h}-e^{-2 \alpha_{B 2} h}\right)
\end{aligned}
$$

The $h$ depicts the phosphor layer density. The subscript " 1 " and " 2 " note the single layer and double-layer remote phosphor configurations. $\beta$ is the conversion coefficient for blue light converting to yellow light. $\gamma$ is the reflection coefficient of the yellow light. The intensities of blue light $(P B)$ and yellow light $(P Y)$ are the light intensity from blue LED, indicated by $P B_{0} . \alpha_{B} ; \alpha_{Y}$ are parameters describing the loss of transmitted energy in blue and yellow lights during their scattering process in the phosphor layer respectively.

The luminous efficiency of pc-LEDs receives significant enhancement when the remote phosphor structure has multiple layers compared to the single layer structure:

$$
\frac{\left(P B_{2}+P Y_{2}\right)-\left(P B_{1}+P Y_{1}\right)}{P B_{1}+P Y_{1}}>0
$$

The scattering of $\mathrm{MgSr}_{3} \mathrm{Si}_{2} \mathrm{O}_{8}: \mathrm{Eu}^{2+}, \mathrm{Mn}^{2+}$ phosphor particles were analyzed by using the Mie-theory [24, 25]. In addition, the scattering cross section of circular particles $C_{s c a}$ can be measured using the following equation with the Mie theory. The efficiency of light power transmission can be defined with Beer's law [26]:

$$
I=I_{0} \exp \left(-\mu_{\text {ext }} L\right)
$$

The $I_{0}$ in this equation is the energy of incident light, $L$ represents the density of phosphor layer (mm) and $\mu_{e x t}$ is the extinction coefficient, which are measured by: $\mu_{e x t}=N_{r}$. $C_{e x t}$, where $N_{r}$ is as the number density distribution of particles $\left(\mathrm{mm}^{-3}\right) . C_{\text {ext }}\left(\mathrm{mm}^{2}\right)$ is the extinction cross-section of phosphor particles.

From (5), it can be seen that the lighting performance of WLEDs with dual-layer phosphor is better than that of WLEDs single-layer phosphor. Therefore, this article confirms that using dual-phosphor layer can result in better luminous flux. The detailed luminous flux are calculated and presented in Figure 5. Figure 5 (a), the concentration of $(\mathrm{Ce}, \mathrm{Tb}) \mathrm{MgAl}_{11} \mathrm{O}_{19}$ : $\mathrm{Ce}: \mathrm{Tb}$ rise from $2 \%$ wt. to $20 \%$ wt., the luminescence quality of WLEDs shows a significant increase. On the other hand, the concentration of $\mathrm{MgSr}_{3} \mathrm{Si}_{2} \mathrm{O}_{8}: \mathrm{Eu}^{2+}, \mathrm{Mn}^{2+}$ has a considerably negative effect on the luminescence quality of WLEDs with $\mathrm{MgSr}_{3} \mathrm{Si}_{2} \mathrm{O}_{8}: \mathrm{Eu}^{2+}, \mathrm{Mn}^{2+}$ layer. Obviously from Figure 5 (b), the luminous flux decreases dramatically when the concentration of $\mathrm{MgSr}_{3} \mathrm{Si}_{2} \mathrm{O}_{8}: \mathrm{Eu}^{2+}, \mathrm{Mn}^{2+}$ starts to rise from $2 \%$ wt. and bottoms out at about $400 \mathrm{~lm}$ with $26 \%$ wt $\mathrm{MgSr}_{3} \mathrm{Si}_{2} \mathrm{O}_{8}: \mathrm{Eu}^{2+}, \mathrm{Mn}^{2+}$ concentration. In addition, Beer's law claims that the extinction of coefficient increase with $\mathrm{MgSr}_{3} \mathrm{Si}_{2} \mathrm{O}_{8}: \mathrm{Eu}^{2+}, \mathrm{Mn}^{2+}$ concentration but is inversely proportional to the transmitted light power. Therefore, having phosphor layers with high thickness can negatively affects the luminous flux due to the excessive amount of $\mathrm{MgSr}_{3} \mathrm{Si}_{2} \mathrm{O}_{8}: \mathrm{Eu}^{2+}, \mathrm{Mn}^{2+}$ concentration. Despite the disadvantage, $\mathrm{MgSr}_{3} \mathrm{Si}_{2} \mathrm{O}_{8}: \mathrm{Eu}^{2+}, \mathrm{Mn}^{2+}$ still achieve astounding result in developing CRI and CQS. Besides using dual-layer phosphor remote structure is much more efficient than a single-layer type. Therefore, the decline cause by $\mathrm{MgSr}_{3} \mathrm{Si}_{2} \mathrm{O}_{8}: \mathrm{Eu}^{2+}, \mathrm{Mn}^{2+}$ is acceptable. The remaining factor is the manufacturers intention from which a suitable concentration of $\mathrm{MgSr}_{3} \mathrm{Si}_{2} \mathrm{O}_{8}: \mathrm{Eu}^{2+}, \mathrm{Mn}^{2+}$ can be applied in mass production of WLEDs. 


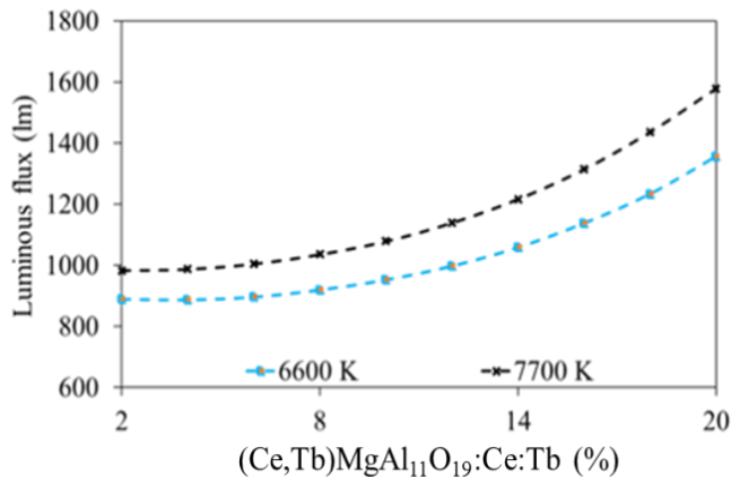

(a)

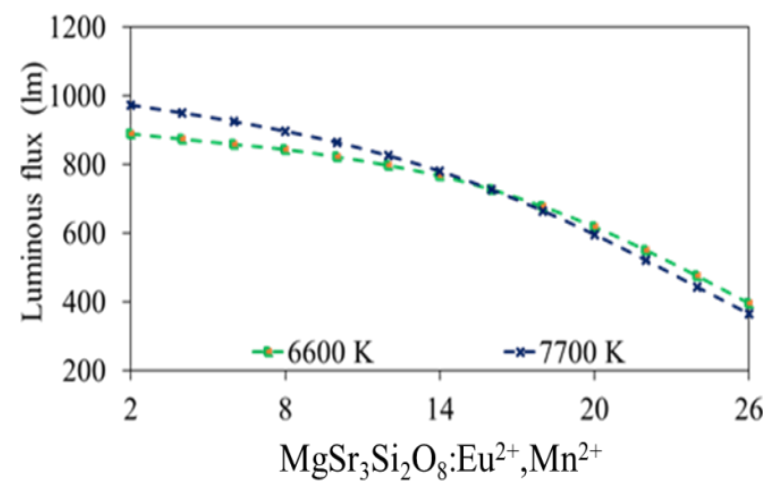

(b)

Figure 5. The luminous flux as a function of the concentration of (Ce,Tb)MgAl11O19:Ce:Tb and MgSr3Si2O8:Eu2+,Mn2+ : (a) GYC; (b) RYC

\section{CONCLUSION}

The paper presents the effect of phosphor green $(\mathrm{Ce}, \mathrm{Tb}) \mathrm{MgAl}_{11} \mathrm{O}_{19}: \mathrm{Ce}: \mathrm{Tb}$ and phosphor red $\mathrm{MgSr}_{3} \mathrm{Si}_{2} \mathrm{O}_{8}: \mathrm{Eu}^{2+}, \mathrm{Mn}^{2+}$ in dual-layer phosphor structure on the indicators of WLEDs chromatic quality and light output. Moreover, this is the first time the detailed comparison between the two type of dual-phosphor layer structure is made. The verification using the Mie theory and the Beer's law has certified that $\mathrm{MgSr}_{3} \mathrm{Si}_{2} \mathrm{O}_{8}: \mathrm{Eu}^{2+}, \mathrm{Mn}^{2+}$ is the reasonable choice to improve color quality. Meanwhile, (Ce, $\left.\mathrm{Tb}\right) \mathrm{MgAl}_{11} \mathrm{O}_{19}: \mathrm{Ce}: \mathrm{Tb}$ is the choice to improve the luminous flux of WLEDs. The results achieved from the two structure is applicable for WLEDs with low color temperature $(6600 \mathrm{~K})$ and configurations with the temperature higher than $7700 \mathrm{~K}$. With these outcomes, this study is able to optimize the chromatic quality of white light, a challenging objective to achieve with remote-phosphor structure, especially with the ones having high color temperature. Thus, this is the valuable information for manufacturers as getting better quality of WLEDs with high color temperatures is still a hard task to complete, and there are not enough references for them to count on. However, there is a disadvantage caused by an insufficient management of phosphor concentration: as the concentrations of $(\mathrm{Ce}, \mathrm{Tb}) \mathrm{MgAl}_{11} \mathrm{O}_{19}: \mathrm{Ce}: \mathrm{Tb}$ or $\mathrm{MgSr}_{3} \mathrm{Si}_{2} \mathrm{O}_{8}: \mathrm{Eu}^{2+}, \mathrm{Mn}^{2+}$ increases excessively, the color quality or luminous flux significantly reduces. Hence, it is important to determine the right concentration for phosphor layers. Depending on the goals and based on the useful information provided in this study, the manufacturers can choose the most appropriate remote phosphor structure and phosphor concentration to produce better quality WLEDs.

\section{REFERENCES}

[1] T. T. Trang, et al., "Excellent luminous flux of WLEDs with flat dual-layer remote phosphor geometry," TELKOMNIKA Telecommunication Computing Electronics and Control, vol. 17, no. 5, pp. 2527-2534, 2019.

[2] P. X. Le, et al., "The Impacts of Distance Between Phosphor Layers on Optical Properties of Triple-Layer Phosphor Structure," Advances in Electrical and Electronic Engineering, vol. 17, no. 1, pp. 81-86, 2019.

[3] S. D. Yu, et al., "Enhanced optical and thermal performance of white light-emitting diodes with horizontally layered quantum dots phosphor nanocomposites," Photonics Research, vol. 6, no. 2, pp. 90-98, 2018.

[4] J. P. You, et al., "Light extraction enhanced white light-emitting diodes with multi-layered phosphor configuration," Optics Express, vol. 18, no. 5, pp. 5055-5060, 2010.

[5] S. W. Jeon, et al., "Improvement of phosphor modeling based on the absorption of Stokes shifted light by a phosphor," Optics Express, vol. 22, no. 105, pp. A1237-A1242, 2014.

[6] X. G. Xu, et al., "High luminescent $\mathrm{Li}_{2} \mathrm{CaSiO}_{4}: \mathrm{Eu}^{2+}$ cyan phosphor film for wide color gamut field emission display," Optics Express, vol. 20, no. 16, pp. 17701-17710, 2012.

[7] A. Žukauskas, et al., "Color rendition engineering of phosphor-converted light-emitting diodes," Optics Express, vol. 21, no. 22, pp. 26642-26656, 2013.

[8] C. H. Chiang, et al., "Effects of Flux Additives on Characteristics of $\mathrm{Y}_{2.95} \mathrm{Al}_{5} \mathrm{O}_{12}: 0.05 \mathrm{Ce}{ }^{3+}$ Phosphor: Thermal Stability and Application to WLEDs," Journal of Display Technology, vol. 11, no. 5, pp. 466-470, 2015.

[9] Z. Z. Zhou, et al., "White light obtainment via tricolor luminescent centers and energy transfer in $\mathrm{Ca}_{3} \mathrm{ZrSi}_{2} \mathrm{O}_{9}: \mathrm{Eu}^{3+}, \mathrm{Bi}^{3+}, \mathrm{Tb}^{3+}$ phosphors," Optical Materials Express, vol. 8, no. 11, pp. 3526-3542, 2018.

[10] O. H. Kwon, et al., "White luminescence characteristics of red/green silicate phosphor-glass thick film layers printed on glass substrate," Optical Materials Express, vol. 6, no. 3, pp. 938-945, 2016.

[11] H. C. Kuo, et al., "Patterned structure of REMOTE PHOSPHOR for phosphor-converted white LEDs," Optics Express, vol. 19, no. 104, pp. A930-A936, 2011. 
[12] C. Bull, D. E. Mason, "The Determination of the Distribution of Electron Trapping States in Phosphors," Journal of the Optical Society of America, vol. 41, no. 10, pp. 718-726, 1951.

[13] G. Y. Lee, et al., "Tunable emission from blue to white light in single-phase $\mathrm{Na}_{0.34} \mathrm{Ca}_{(0.66-\mathrm{x}-\mathrm{y})} \mathrm{Al}_{1.66} \mathrm{Si}_{2.34} \mathrm{O}_{8}$ : $\mathrm{xEu}^{2+}, \mathrm{yMn}^{2+}(\mathrm{x}=0.07)$ phosphor for white-light UV LEDs," Optics Express, vol. 21, no. 3, pp. 3287-3297, 2013.

[14] C. T. Yeh, et al., "Luminescence material characterizations on laser-phosphor lighting techniques," Optics Express, vol. 27, no. 5, pp. 7226-7236, 2019.

[15] O. H. Kwon, et al., "Simple prismatic patterning approach for nearly room-temperature processed planar remote phosphor layers for enhanced white luminescence efficiency," Optical Materials Express, vol. 8, no. 10, pp. 3230-3237, 2018.

[16] T. T. Trang, et al., "Improving luminous flux and color homogeneity of dual-layer phosphor sctructure," TELKOMNIKA Telecommunication Computing Electronics and Control, vol. 17, no. 5, pp. 2643-2649, 2019.

[17] X. Y. Huang, et al., "High-brightness and high-color purity red-emitting $\mathrm{Ca}_{3} \mathrm{Lu}(\mathrm{AlO})_{3}\left(\mathrm{BO}_{3}\right)_{4}: \mathrm{Eu}^{3+}$ phosphors with internal quantum efficiency close to unity for near-ultraviolet-based white-light-emitting diodes," Optics Letters, vol. 43, no. 6, pp. 1307-1310, 2018.

[18] T. H. Yang, et al., "Stabilizing CCT in pcW-LEDs by self-compensation between excitation efficiency and conversion efficiency of phosphors," Optics Express, vol. 25, no. 23, pp. 29287-29295, 2017.

[19] Y. P. Chang, et al., "An advanced laser headlight module employing highly reliable glass phosphor," Optics Express, vol. 27, no. 3, pp. 1808-1815, 2019.

[20] Y. Peng, et al., "Thermally stable WLEDs with excellent luminous properties by screen-printing a patterned phosphor glass layer on a microstructured glass plate," Applied Optics, vol. 56, no. 12, pp. 3270-3276, 2017.

[21] H. L. Shi, et al., "Luminescence properties of YAG:Ce, Gd phosphors synthesized under vacuum condition and their white LED performances," Optical Materials Express, vol. 4, no. 4, pp. 649-655, 2014.

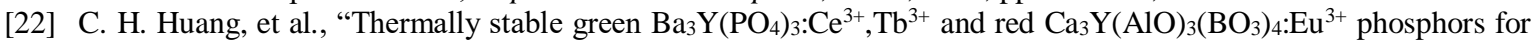
white-light fluorescent lamps," Optics Express, vol. 19, no. 101, pp. A1-A6. 2011.

[23] F. Aquino, et al., "Effect of laser speckle on light from laser diode-pumped phosphor-converted light sources," Applied Optics, vol. 56, no. 2, pp. 278-283, 2017.

[24] P. Acuña, et al., "Power and photon budget of a remote phosphor LED module," Optics Express, vol. 22, no. 104, pp. A1079-A1092, 2014.

[25] J. R. Oh, et al., "Full down-conversion of amber-emitting phosphor-converted light-emitting diodes with powder phosphors and a long-wave pass filter," Optics Express, vol. 18, no. 11, pp. 11063-11072, 2010.

[26] J. Cheng, et al., "Synthesis and photoluminescence properties of $\mathrm{Sr}_{4} \mathrm{La}\left(\mathrm{PO}_{4}\right)_{3} \mathrm{O}: \mathrm{RE}^{3+}(\mathrm{RE}=\mathrm{Eu} / \mathrm{Tb} / \mathrm{Ce})$ phosphors," Chinese Optics Letters, vol. 15, no. 12, pp. 121602, 2017. 